\title{
HERANÇA DA INFLORESCÊNCIA COMPOSTA DA CULTIVAR DE FEIJÃO-CAUPI CACHEADO
}

\author{
Inheritance of composite inflorescence of cowpea cacheado cultivar
}

\author{
Cristina de Fátima Machado¹, Francisco Rodrigues Freire Filho², Valdenir Queiroz Ribeiro ${ }^{3}$, \\ Débora Samara Sousa Costa ${ }^{4}$, Antônia Fernandes de Amorim ${ }^{5}$
}

\begin{abstract}
RESUMO
O feijão-caupi [Vigna unguiculata (L.) Walp.] apresenta inflorescência simples. Entretanto, foram identificados dois genes mutantes recessivos $c i$ e $b p$ que condicionam a produção de inflorescência composta na espécie. Essa característica também foi constatada na cultivar local Cacheado. Objetiva-se com este trabalho determinar o controle genético dessa característica. Foram realizados dois cruzamentos Freezergreen x Cacheado e Bettegreen x Cacheado. Os cruzamentos e a obtenção das gerações $\mathrm{F}_{1}, \mathrm{~F}_{2} \mathrm{e}$ retrocruzamentos, com ambos parentais, foram realizados em casa-de-vegetação. No experimento de campo foi utilizado o delineamento de blocos casualizados com quatro repetições. Cada parcela foi representada por uma fileira de $10,0 \mathrm{~m}$, com espaçamento entre fileiras de $0,80 \mathrm{~m}$ e dentro da fileira de $0,50 \mathrm{~m}$, sendo cultivada uma planta por cova. Esse experimento foi conduzido sob irrigação por aspersão convencional, na Embrapa Meio-Norte, em Teresina, Piaú, nos anos 1998/1999. O teste de $\chi^{2}$ foi usado para a análise dos dados. As segregações das gerações $\mathrm{F}_{2}$ se ajustaram à proporção de 3 inflorescências simples: 1 inflorescência composta e as dos retrocruzamentos com o parental Cacheado à proporção de 1 inflorescência simples: 1 inflorescência composta. A partir desses resultados depreende-se que a inflorescência composta presente na cultivar cacheado tem herança monogênica recessiva.
\end{abstract}

Termos para indexação: Vigna unguiculata, Controle genético, Melhoramento genético.

\begin{abstract}
Cowpea [Vigna unguiculata (L.) Walp.] presents simple inflorescence. However, two recessive mutant genes $c i$ and $b p$ that produce composite inflorescence were identified in cowpea. This characteristic was also observed in the brazillian local cultivar Cacheado. The aim of this work was to investigate the genetic control of the composite inflorescence of Cacheado Cultivar. Two crosses were performed Freezergreen $x$ Cacheado and Bettegreen $x$ Cacheado. The crosses and the $\mathrm{F}_{1}, \mathrm{~F}_{2}$ and the backcrosses were obtained in greenhouse. In the field trial the randomized complete block design with four replications was used. Each plot was represented by a row of $10 \mathrm{~m}$ long with 20 plants. The spacing between rows was of the $0,80 \mathrm{~m}$. The experiment was carried out in the field, under irrigation by conventional aspersion at Embrapa Meio-Norte, Teresina city, Piauí Statate, the years of 1998 and 1999. The Qui Square test was used to analyse the data. The segregation pattern in both $\mathrm{F}_{2}$ generations fitted the 3 simple inflorescences: 1 composite inflorescence ratio and the backcrosses to the Cacheado cultivar fitted the 1 simple inflorescence: 1 composite inflorescence ratio. The inheritance study showed that composite inflorescence of the Cacheado cultivar is controlled by a single recessive gene.
\end{abstract}

Index terms: Vigna unguiculata, Genetic control, Genetic breeding.

\section{(Recebido em 23 de agosto de 2006 e aprovado em 11 de junho de 2007)}

\section{INTRODUÇÃO}

O feijão-caupi é uma planta herbácea, autógama, anual, cuja região de origem mais provável situa-se na parte oeste e central da África. É uma das leguminosas melhor adaptada, versátil e nutritiva entre as espécies cultivadas, sendo um importante alimento e componente essencial dos sistemas de produção nas regiões secas dos trópicos, cobrindo parte da Ásia, Estados Unidos, Oriente Médio e Américas Central e do Sul (SINGH et al., 2002). Nessas regiões o feijão-caupi constitui-se em uma das principais fontes de proteína vegetal, notadamente para as populações de menor poder aquisitivo (GRANGEIRO et al., 2005).

No Brasil, o feijão-caupi é mais cultivado nas áreas semi-áridas do Nordeste brasileiro. É uma espécie rústica bem adaptada às condições de clima e solo da região e possuidora de uma ampla variabilidade genética, ampla capacidade de adaptação, alto potencial produtivo e excelente valor nutritivo, características estas que conferem à cultura grande valor atual e estratégico (FREIRE FILHO et al., 2006).

\footnotetext{
'Engenheiro Agrônomo, Doutora - Departamento de Melhoramento Genético do Feijão-Caupi - Embrapa-Centro de Pesquisa Agropecuária do Meio Norte/ CPAMN - Avenida Duque de Caxias, 5650 - Cx. P. 01 - 64006-220 - Teresina, PI - crisagronoma@yahoo.com.br - Bolsista do CNPq

'Engenheiro Agrônomo, Doutor - Departamento de Melhoramento Genético do Feijão-Caupi - Embrapa-Centro de Pesquisa Agropecuária do Meio Norte/ CPAMN - Avenida Duque de Caxias, 5650 - Cx. P. 01 - 64006-220 - Teresina, PI -freire@cpamn.embrapa.br

${ }^{3}$ Engenheiro Agrônomo, Mestre - Departamento de Estatística - Embrapa-Centro de Pesquisa Agropecuária do Meio Norte/CPAMN - Avenida Duque de Caxias, 5650 - Cx. P. 01 - 64006-220 - Teresina, PI -valdenir@cpamn.embrapa.br

${ }^{4}$ Engenheiro Agrônomo - Universidade Federal do Piauí/UFPI - Campus Universitário Ministro Petrônio Portella - $64049-550$ - Teresina, PI, Brasil belasamara@bol.com.br

${ }^{5}$ Engenheiro Agrônomo - Universidade Federal do Piauí/UFPI - Campus Universitário Ministro Petrônio Portella - 64049-550 - Teresina, PI, Brasil suzefernandes@bol.com.br
} 
A planta apresenta dois tipos de ramificações principais: o determinado e o indeterminado. No primeiro tipo, o caule produz um número limitado de nós e pára de crescer quando emite uma inflorescência. Nas plantas de ramificação indeterminada, o caule continua crescendo e emitindo novas ramas secundárias e gemas florais (ARAÚJO et al., 1981). Esse tipo é o mais comumente cultivado no Brasil.

O feijão-caupi, apresenta inflorescências simples. Entretanto, foram identificados dois genes recessivos $c i$ (SEN \& BOWAL, 1961) e $b p$ (FAWOLE \& AFOLOBI, 1983) que condicionam a produção de inflorescências compostas em feijão-caupi.

A cultivar local Cacheado, coletada no Estado do Ceará, em 1973, também apresenta inflorescências compostas. Essa característica da cultivar Cacheado foi descrita por Araújo et al. (1981). Até o presente, entretanto, não foi realizado nenhum estudo sobre o controle genético dessa característica da cultivar Cacheado.

A inflorescência composta é uma característica que altera morfologicamente a parte reprodutiva da planta. Desse modo, é importante que esse gene seja introduzido em genótipos com diferentes tipos de arquitetura de planta, para se avaliar se o mesmo produz impacto positivo na produtividade do feijão-caupi. Neste contexto, objetiva-se com este trabalho estudar a herança da inflorescência composta da cultivar Cacheado de modo a fornecer subsídios para o melhoramento genético do feijão-caupi.

\section{MATERIAL E MÉTODOS}

Foi utilizada a cultivar de feijão-caupi Cacheado, com inflorescência composta, registrada no Banco de Germoplasma do Departamento de Fitotecnia do Centro de Ciências Agrárias da Universidade Federal do Ceará com o código CE-28, no Banco de Germoplasma da Embrapa Meio-Norte com o código TE-28 e no Banco de Germoplasma da Embrapa Recursos Genéticos e Biotecnologia com o código BFC-28, e as cultivares
Freezergreen (CHAMBLISS, 1979) e Bettegreen (FERY et al., 1993), com inflorescência simples. As três cultivares foram obtidas junto ao Banco de Germoplasma de feijãocaupi da Embrapa Meio-Norte (Tabela 1).

$\mathrm{O}$ trabalho envolveu três etapas. A primeira etapa constou da realização dos cruzamentos dos parentais em casa-de-vegetação para obtenção de sementes $F_{1}$ Nessa etapa, cada parcela foi representada por uma fileira de 2,0 $\mathrm{m}$; o espaçamento entre fileiras foi de $0,50 \mathrm{~m}$ e entre covas de $0,15 \mathrm{~m}$, com uma planta por cova.

Foram realizados dois cruzamentos sendo, o primeiro: Freezergreen x Cacheado e o segundo: Bettegreen x Cacheado. Os cruzamentos foram realizados segundo Kheradnam \& Niknejad (1971) e Zary \& Miller Júnior (1982).

A segunda etapa do trabalho, também em casa-devegetação, constou da obtenção das gerações $F_{2}$ e dos retrocruzamentos. Em ambos os cruzamentos, foram obtidas as gerações $F_{2}$, por autofecundação natural das gerações $F_{1}$, e foram realizados retrocruzamentos das gerações $F_{1}$, com ambos os parentais. Nessa etapa, cada parcela foi representada por uma fileira de $2,0 \mathrm{~m}$, o espaçamento entre fileiras foi de $0,50 \mathrm{~m}$ e entre covas de $0,15 \mathrm{~m}$ com uma planta por cova.

A terceira etapa constou de um experimento em campo, em cultivo irrigado por aspersão convencional. Utilizou-se o delineamento experimental de blocos casualizados com quatro repetições. Cada parcela foi representada por uma fileira de $10,0 \mathrm{~m}$, o espaçamento entre fileiras foi de $0,80 \mathrm{~m}$ e dentro da fileira $0,50 \mathrm{~m}$, sendo cultivada uma planta por cova. Todos os trabalhos foram realizados em área experimental da Embrapa Meio-Norte, em Teresina, Piauí, nos anos 1998/1999.

Os dados foram coletados em plantas individuais. Em ambos os cruzamentos, nos parentais e nas gerações $\mathrm{F}_{1}, \mathrm{~F}_{2}$ e nos retrocruzamentos, as plantas foram classificadas, na maturidade, de acordo com o tipo de pedúnculo em normal ou ramificada. Os dados das

TABELA 1 - Origem e algumas características das cultivares de feijão-caupi utilizadas nos cruzamentos.

\begin{tabular}{lcccc}
\hline Cultivar & Origem & $\begin{array}{c}\text { Tipo de } \\
\text { inflorescência }\end{array}$ & Cor do grão & $\begin{array}{c}\text { Peso de 100 } \\
\text { grãos (g) }\end{array}$ \\
\hline Freezergreen & EUA & Simples & Verde & 17,9 \\
Bettergreen & EUA & Simples & Verde & 12,2 \\
Cacheado & Universidade Federal & Composta & Branca & 18,1 \\
\hline
\end{tabular}


gerações $\mathrm{F}_{2}$ e retrocruzamentos com o parental Cacheado foram analisados pelo teste de $\chi^{2}$ (CRUZ, 2001).

\section{RESULTADOS E DISCUSSÃO}

As gerações $F_{1}$ de ambos os cruzamentos apresentaram inflorescências normais. Similarmente, todas as plantas nos retrocruzamentos com os parentais com inflorescência normal também apresentaram inflorescências normais (Tabela 2). Isso indica que a inflorescência composta presente na cultivar Cacheado é uma característica recessiva.

Com base nos resultados obtidos por Fawole \& Afolobi (1983) e Sen \& Bowal (1961) a hipótese mais provável é que a característica inflorescência composta presente na cultivar Cacheado seja controlada por um único gene. Desse modo, os dados observados nas gerações $\mathrm{F}_{2}$ e retrocruzamentos com o parental Cacheado foram comparados pelo teste de $\chi^{2}$ com as proporções fenotípicas esperadas de 3 inflorescências simples: 1 inflorescência composta e 1 inflorescência simples: 1 inflorescência composta, respectivamente.

Em ambos os cruzamentos, as gerações $F_{2}$ se ajustaram à proporção de 3 inflorescências simples: 1 inflorescência composta e os retrocruzamentos à de 1 inflorescência simples: 1 inflorescência composta. Esses resultados sugerem que a inflorescência composta da cultivar Cacheado tem herança monogênica recessiva. Essa característica se assemelha muito a estudada por Fawole \& Afolobi (1983), mas não se pode afirmar que se trata do mesmo gene; somente com um teste de alelismo poderá dirimir essa dúvida.

Com relação às inflorescências de feijão-caupi, verifica-se que o pedúnculo floral da cultivar Cacheado, bifurca-se a uma certa altura, produzindo novos segmentos que produzirão flores e frutos. A bifurcação se dá na axila de uma folha lanceolada, de forma diferente das folhas normais que se desenvolvem ao mesmo tempo que o desenvolvimento dos ramos florais produzidos (Figura 1b). Já na inflorescência simples, o pedúnculo que suporta as gemas florais são longos, sugerindo que cada segmento produzido representa um novo pedúnculo (Figura 1a).

TABELA 2 - Herança do pedúnculo ramificado da cultivar de feijão-caupi Cacheado.

\begin{tabular}{|c|c|c|c|c|c|c|}
\hline \multirow[t]{2}{*}{ Cruzamentos } & \multirow{2}{*}{$\begin{array}{l}\text { Número de } \\
\text { plantas }\end{array}$} & \multicolumn{2}{|c|}{ Tipo de inflorescência } & \multirow{2}{*}{$\begin{array}{c}\text { Freqüiência } \\
\text { esperada }\end{array}$} & \multirow[t]{2}{*}{$\chi^{2}$} & \multirow[t]{2}{*}{$P$} \\
\hline & & Simples & Composta & & & \\
\hline \multicolumn{7}{|l|}{ Cruzamento 1} \\
\hline Freezergreen $(\mathrm{Fg})$ & 11 & 11 & & & & \\
\hline Cacheado (Ch) & 29 & & 29 & & & \\
\hline $\mathrm{F}_{1}(\mathrm{Fg} \times \mathrm{Ch})$ & 5 & 5 & & & & \\
\hline $\mathrm{F}_{2}(\mathrm{Fg} \times \mathrm{Ch})$ & 255 & 207 & 48 & $3: 1$ & 5,18 & $0,05-0,02$ \\
\hline $\mathrm{RC}_{1}\left(\mathrm{Fg} \times \mathrm{F}_{1}\right)$ & 6 & 6 & & & & \\
\hline $\mathrm{RC}_{2}\left(\mathrm{Ch} \times \mathrm{F}_{1}\right)$ & 5 & 2 & 3 & $1: 1$ & 0,20 & $0,70-0,50$ \\
\hline \multicolumn{7}{|l|}{ Cruzamento 2} \\
\hline Bettergreen (Bg) & 22 & 22 & & & & \\
\hline Cacheado (Ch) & 29 & & 29 & & & \\
\hline $\mathrm{F}_{1}(\mathrm{Bg} \times \mathrm{Ch})$ & 14 & 14 & & & & \\
\hline $\mathrm{F}_{2}(\mathrm{Bg} \times \mathrm{Ch})$ & 247 & 195 & 52 & $3: 1$ & 2,05 & $0,20-0,10$ \\
\hline $\mathrm{RC}_{1}\left(\mathrm{Bg} \times \mathrm{F}_{1}\right)$ & 24 & 24 & & & & \\
\hline $\mathrm{RC}_{2}\left(\mathrm{Ch} \times \mathrm{F}_{1}\right)$ & 28 & 17 & 11 & $1: 1$ & 1,28 & $0,30-0,20$ \\
\hline
\end{tabular}




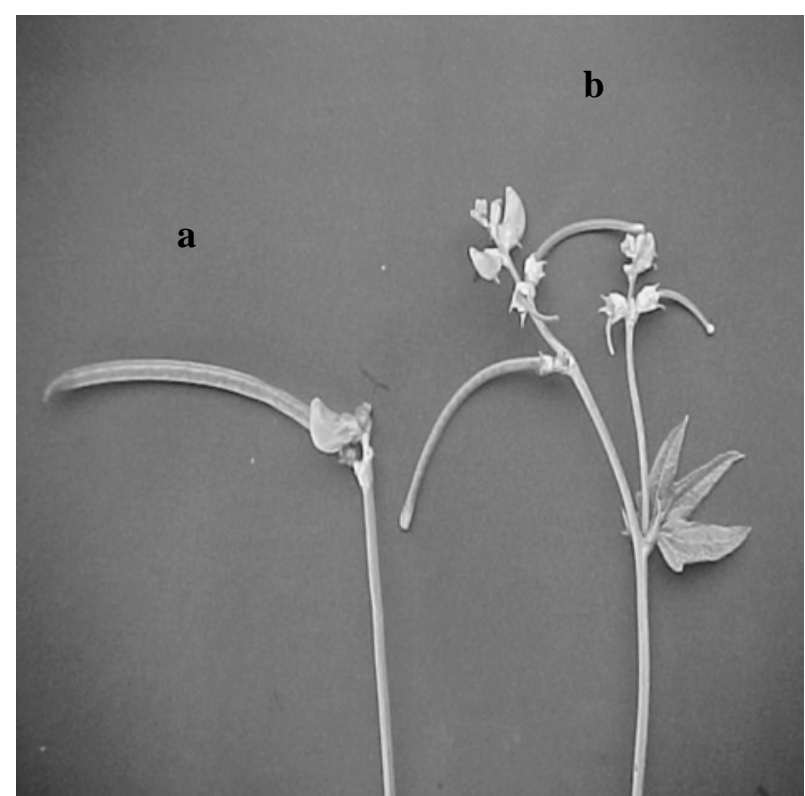

FIGURA 1 - Inflorescências de feijão-caupi: (a) simples; (b) composta.

\section{CONCLUSÃO}

A inflorescência composta da cultivar Cacheado tem herança monogênica recessiva.

\section{REFERÊNCIAS BIBLIOGRÁFICAS}

ARAÚJO, J. P. P. de; SANTOS, A. A. dos; CARDOSO, M. J.; WATT, E. E. Nota sobre a ocorrência de uma inflorescência ramificada em caupi Vigna unguiculata (L.) Walp. Subsp, unguiculata no Brasil. Revista Ciência Agronômica, Fortaleza, v. 12, n. 1/2, p. 187-193, 1981.

CHAMBLISS, O. L. 'Freezegreen' southernpea. HortScience, Saint Joseph, v. 14, n. 2, p. 193, 1979.

CRUZ, C. D. Programa Genes: versão Windows: aplicativo computacional em genética e estatística. Viçosa: UFV, 2001. $648 \mathrm{p}$.
FAWOLE, I.; AFOLABI, O. Genetic control of a branching peduncle mutant of cowpea, Vigna unguiculata (L.) Walp. Journal of Agricultural Science, Cambridge, v. 100, p. 473-475, 1983.

FERY, R. L.; DUKES, P. D.; MAGUIRE, F. P. "Bettergreen" southernpea. HortScience, Saint Joseph, v. 28, p. 856, 1993.

FREIRE FILHO, F. R.; RIBEIRO, V. Q.; BARRETO, P. D.; SANTOS, C. A. F. Melhoramento genético de caupi [Vigna unguiculata (L.) Walp.] na região do Nordeste. Disponível em: 〈http://www.cpatsa.embrapa.br>. Acesso em: 10 jan. 2006.

GRANGEIRO, T. B.; CASTELLÓN, R. E. R.; ARAÚJO, F. M. M. C. de; SILVA, S. M. de S. e; FREIRE, E. de A.; CAJAZEIRAS, J. B.; AMARAL NETO, M.; GRANGEIRO, M. B.; CAVADA, B. S. Composição bioquímica da semente. In: FREIRE FILHO, F. R.; LIMA, J. A. de A.; RIBEIRO, V. Q. (Eds.). Feijão-caupi: avanços tecnológicos. Brasília, DF: Embrapa Informação Tecnológica, 2005. p. 338-365.

KHERADNAM, M.; NIKNEJAD, M. Crossing technique in cowpeas. Iranian Journal of Agricultural Research, Haryana, v. 1, n. 1, p. 57-58, 1971.

SEN, N. K.; BHOWAL, J. G. Genetics of Vigna sinensis (L.) Savi. Genética, [S.1.], v. 32, p. 247-266, 1961.

SINGH, B. B.; EHLERS, J. D.; SHARMA, B.; FREIRE FILHO, F. R. Recent progress in cowpea breeding. In: FATOKUN, C. A.; TARAWALI, S. A.; SINGH, B. B.; KORMAWA, P. M.; TAM?Ò, M. (Eds.). Challenges and opportunities for enhancing sustainable cowpea production. Ibadan: IITA, 2002. p. 22-40.

ZARY, K. W.; MILLER JUNIOR, J. C. Comparisson of two methods of hand-crossing Vigna unguiculata (L.) Walp. HortScience, Saint Joseph, v. 15, n. 2, p. 179, 1980. 